\title{
"Me inscribieron porque peleaba mucho con mi mamá para hacer la tarea". Encuentros etnográficos con niños en un club de tareas
}

\author{
"I was enrolled here because I kept arguing with my mom \\ about the homework". Ethnographic encounters with children \\ in a homework club
}

DOI: https://doi.org/10.32870/dse.v0i20.605

Paola Sánchez Ramos* José Luis Arriaga Ornelas**

\begin{abstract}
Resumen
Los espacios educativos se han diversificado. La escuela ya no es el único ámbito donde tienen lugar procesos de enseñanza-aprendizaje. Nuevos y disímbolos espacios son hoy el escenario donde distintos agentes construyen sistemas de significación y acción en torno a procesos educacionales. Este artículo se ocupa de un espacio educativo emergente en México: los clubes o talleres de tareas. Se ofrece una aproximación etnográfica a él, a través de la cual se obtuvieron datos importantes sobre sus protagonistas: los niños y niñas que pasan en él varias horas cada día, llevando a cabo actividades que tradicionalmente se realizaban en casa, con otros miembros de la familia (comer, hacer las tareas escolares, jugar, pasar el tiempo). Los resultados permiten ver que estos menores, como agentes sociales, hacen del club de tareas un lugar en el que trabajan cosas "de la escuela" sin la coerción de las calificaciones; donde hacen cosas "de la casa" sin la presencia autoritaria de los papás; e incluso donde juegan con una comunidad más amplia que la de los hermanos. En el club de tareas se genera una agencia infantil muy particular que, sin embargo, no es ajena a las relaciones de poder de una sociedad adultocéntrica, pero que negocia de modos muy particulares lo que puede hacer el niño en ese contexto concreto.
\end{abstract}

Palabras clave: espacio educativo - club de tareas - niños, agencia - educación no formal.

\section{Abstract}

Educational spaces have become diversified. School is no longer the only place where teaching-learning processes take place. New and very different spaces are now the stage where different agents build systems of meaning

\footnotetext{
* Estudiante en proceso de titulación de la licenciatura en Antropología Social de la Universidad Autónoma del Estado de México. México. sarauaem@gmail.com

** Doctor en Ciencias Sociales. Profesor-investigador de Tiempo Completo definitivo, Facultad de Antropología, Universidad Autónoma del Estado de México. Miembro del Sistema Nacional de Investigadores, nivel I. Líder del Cuerpo Académico “Patrones culturales de las relaciones sociales. México.jlarriagao@gmail.com
} 
and action around educational processes. This article deals with an emerging educational space in Mexico: the homework clubs. It offers an ethnographic perspective and important data about the children who spend several hours each day there doing activities that used to be done at home with other members of the family (eating meals, doing homework, playing, spending time with others). The results show that these children, as social agents, make the homework club a place where they do tasks "from school" without the coercion of the grades, where they perform tasks "of the house" without the authoritarian presence of the parents, and where they even play with a broader community than that of their siblings. The homework club generates a special kind of childhood agency which is not exempt from the power relationships of an adult-centered society but negotiates in very particular ways what the child can do in that specific environment.

Key words: educational space - homework club - children-agency - informal education.

\section{Introducción}

El trabajo etnográfico es una "metodología artesanal" (Guber, 2011: 15) cuyo valor reside en conocer de primera mano cómo viven, actúan y significan las personas su realidad. En medio del debate acerca de la sobreutilización del término etnografía dentro de las ciencias sociales, misma que podría conducir a una inflación que termine devaluándola como vía para la generación de conocimiento (Ingold, 2017), este trabajo se propone contribuir a la apuesta por seguir procediendo etnográficamente para la generación de un conocimiento que permite al investigador salir de sus tópicos y dejarse penetrar por otra topología (Sánchez-Parga, 2010: 70). Cuando se procede etnográficamente y se hace trabajo de campo, en el sentido antropológico, hay una labor colaborativa en la que investigador y agentes sociales se involucran mutuamente en un movimiento de correspondencia (Ingold, 2013). En ese itinerario epistemológico hay un componente social del conocimiento (Bloor, 2014), que en el presente trabajo consiste en la colaboración mediante encuentros etnográficos (Fabian, 2007) con actores a los que no siempre se presta mucha atención en las perspectivas etnográficas y educativas: los niños, niñas y adolescentes (Milstein, et al., 2011).

Este trabajo ubica, se acerca y describe un espacio educativo del que existen pocos estudios: un club de tareas. No se trata de una escuela a la que el pensamiento moderno ubica como la institución social encargada de la educación (Canfux, 2000); se trata de un escenario distinto a aquel en el que suele ubicarse el fenómeno educativo (Rosas, 2018); por su novedad y ambigüedad, también está apartado del espacio que reivindica la pedagogía como objeto de estudio (Pontón, 2002); del mismo modo, no se corresponde con los linderos del objeto que ha animado la investigación educativa en México, misma que puede remontarse a mediados del siglo pasado (Martínez, 1996). Por supuesto, tampoco es de donde ha surgido la noción "cultura escolar" a la que se refieren los trabajos sobre prácticas escolares, sobre todo desde la antropología (Elías, 2015). Los clubes de tareas no entregan ningún certificado, no asignan calificaciones, no tienen

Diálo@os sobre Educación año 11 | número 20 | enero-junio 2020 | ISSN 2007-2171 
reconocimiento oficial ni supervisión de autoridad educativa alguna. Y, sin embargo, pueden considerarse un espacio educativo porque - al menos para los padres y los encargados del club- hay una clara intención de propiciar aprendizajes y para ello se organizan espacio, tiempo y acciones de los niños durante su estancia en el club.

Probablemente, a un club o taller de tareas se le pueda ubicar en la educación no formal debido a la extensión del concepto:"toda actividad educativa organizada, sistemática, realizada fuera del marco del sistema oficial, para facilitar determinadas clases de aprendizaje a subgrupos particulares de la población, tanto de adultos como niños(as)" (Trilla, 2009: 112). Sin embargo, lograr su clasificación se encuentra lejos de permitirnos conocer cómo transcurre su día a día: las dinámicas, los procesos, los actores, los símbolos; en otras palabras, casi nada se sabe hasta ahora de cómo esos espacios son constituidos en lugares que albergan un conjunto importante de acciones, creando significados para ello y para su entorno. Y quienes llevan a cabo esto de manera protagónica son los niños y niñas que pasan gran parte de sus días en dicho lugar. Por eso el presente artículo reporta los resultados de una investigación que se propuso conocer qué pasa en los clubes de tareas, y lo hizo procediendo etnográficamente, reconociendo "la agencia de niños, niñas y adolescentes como sujetos de las investigaciones y como productores y reproductores activos de la cultura" (Milstein et al., 2011: 15).

En este trabajo se cristaliza un esfuerzo por hacer visibles dos cosas: la primera es la emergencia en México de espacios educativos que difícilmente pueden ser definidos con exactitud, debido a que se encuentran en los linderos de la educación no formal e informal, y en donde están pasando gran parte de su tiempo muchos niños que no tienen condiciones para permanecer en su casa después de concluidas sus labores de la actividad escolar regular; y, la segunda, es la agencia de los niños que acuden a un club de tareas y en él despliegan performativamente su ser social como niños. Para abordar el término de agencia se retoman las nociones de Anthony Giddens (1986) y Pierre Bourdieu (1991), que sugieren mirar al sujeto-agente como un actor situado en contextos estructurados y estructurantes. Esta perspectiva ha sido desarrollada por gente como Ema (2004) y Magistris (2018) para referir la capacidad de actuar, no como propiedad individual sino como posibilidad compartida; o, dicho en otras palabras, los sujetos expresan su agencia al actuar en un contexto determinado que los constriñe. Y, para el caso específico de los niños en sociedades como las latinoamericanas, ese contexto que les constriñe: "sigue partiendo de relaciones de subordinación, adultocéntricas, dentro de un proceso más amplio de jerarquización social atravesado por relaciones de minoridad" (Magistris, 2018: 24). Así que en este trabajo se hablará tanto de las acciones de los niños que acuden a un club de tareas como de la posibilidad de actuar que tienen en tanto menores en edad escolar, siguiendo la propuesta de Martha Nussbaum, para quien la agencia es "la capacidad de acción del individuo" (2012: 50). 
Los llamados club o taller de tareas son básicamente un servicio educativo (Solano, 2001), que también puede ser pensado como un apoyo pedagógico (Arellano, 2012) o la forma de brindar atención especial a estudiantes con problemas como bajo rendimiento académico, riesgo de deserción o rezago en general (Hernández, 2003). Pero de manera reciente han sido pensados como un "modelo de negocio" asequible a quienes tienen estudios en psicología, pedagogía o experiencia docente y quieren emprender un negocio "desde casa" (Ideas de negocios, 2019; Alto Nivel, 2010; Entrepreneur, 2008). No existe información consolidada acerca de cuántos clubes de tareas existen, dónde y con qué características operan en México. Lo que sí existe son indicadores acerca del tiempo, frecuencia e importancia que tienen las tareas escolares (INEE, 2009, 2014, 2015), mismos que son interpretados por algunos como indicios de un "mercado prácticamente virgen" (Entrepreneur, 2008) para quien busca emprender un negocio sin salir de casa.

Para este trabajo resulta de especial relevancia subrayar el sentido socialmente asignado a las tareas escolares: "interrelacionan al docente con el factor familia; involucrando, o lo que es mejor incluyendo, en la educación del menor" (Salinas y Molina, 2009: 5). Lo anterior quedaría anulado cuando se asigna a alguien externo a la familia la responsabilidad de que el estudiante realice sus tareas. Cooper (1994) asegura que el propósito de la tarea se divide en instruccional y no instruccional; en el primer aspecto, ayuda a practicar o revisar un material visto en clase, introducir a una lección nueva a través de la investigación previa y extender los conocimientos aprendidos a situaciones nuevas. Pero entre los objetivos no instruccionales están el establecer comunicación entre padres e hijos, cumplir órdenes de los administradores escolares y castigar a los alumnos bajo ciertas circunstancias.

En contraste, los clubes o talleres de tareas se piensan dirigidos a aquellos casos en los que "ambos padres trabajan [y] es difícil que tengan tiempo para ayudar a sus hijos a hacer las tareas escolares. En respuesta, surgieron los 'clubes de tareas', lugares donde los chicos, en la tarde, cuentan con profesores especializados que les apoyan en este aspecto" (Entrepreneur, 2008). Es verdad que en algún momento también la máxima autoridad en materia educativa en México (la Secretaría de Educación Pública) "ha incorporado, en algunas de sus escuelas primarias, un programa piloto verspertino, en el cual los niños acuden a hacer sus tareas al igual que llevan a cabo algunas actividades de tipo recreativo" (Solano, 2001: 1). En ambos casos, hay un claro desplazamiento del propósito no instruccional de que la tarea pueda establecer comunicación entre padres e hijos, al que se refiere Cooper (1994).

No obstante lo anterior, lo cierto es que los talleres o clubes de tareas existen, que los padres envían a ellos a sus hijos, que los mismos pasan varias horas al día en él y están a cargo de personas con cierta formación pedagógica, mismas que ofrecen servicios que van desde la regularización -es decir, el apoyo para alcanzar el desempeño esperado para su nivel educativo en la escuela regular-, hasta los cursos extracurriculares, la realización de las tareas e inclusive 
la alimentación. En tanto lugares que operan, los mismos se convierten en escenarios donde distintos tipos de agentes interactúan, realizan distintos tipos de acciones y producen sistemas de significación y acción. Es justo ahí en donde se realizó la investigación, poniendo especial atención a qué hacen los niños y cómo lo piensan.

\section{Sobre la forma de procedimiento de la investigación}

La investigación cuyos resultados se ofrecen en el presente artículo, se realizó en un club de tareas ubicado en la ciudad de Toluca, Estado de México, que viene funcionando desde hace cinco años. Se denomina "Club de Tareas Ingenium", está ubicado en la zona poniente de la ciudad, en una colonia de clase media. El club abrió sus puertas a mediados del mes de mayo de 2015 y originalmente surge - refieren sus fundadoras - como una propuesta dirigida a grupos de infantes con discapacidades motrices y bajo una condición medicada. Debido a la demanda, da un giro y se abre al público en general, para auxiliar en la regularización de materias de preescolar, primaria y secundaria. Actualmente atiende a 18 niños. Para realizar la investigación se acudió a este club durante dos meses, buscando el encuentro etnográfico con los niños. Básicamente, se buscó conocer el modo en que se desenvuelve en su propio contexto, para lo cual la autora se insertó en el club de tareas, no como una maestra sino como alguien que asistía a las maestras, lo cual le permitió tomar parte de las actividades ahí desarrolladas. El encuentro con los niños y niñas que habitualmente están ahí, fue abierto y sostenido durante los horarios (matutino y vespertino) en que acuden. Se evitó grabarlos o videofilmarlos para evitar intimidación, sesgo o predisposición. Se interactuó con ellos durante sus actividades habituales en el club y, adicionalmente, se realizaron con ellos dinámicas lúdicas en las que se buscaba construir confianza y familiaridad, pero también identificar sus formas de expresar el cómo se conciben a sí mismos, a su familia, a su escuela y al propio club de tareas.

Se vio a los niños como agentes que participan en la construcción significativa del club de tareas donde se llevó a cabo la investigación, pero se asumió que su agencia tiene lugar dentro de un contexto que les constriñe, que les estructura en tanto que es un marco de suposiciones, modelos, propósitos y significados compartidos socialmente (Bloor, 2014); así que, al ser ellos niños y ser estudiantes, su capacidad de acción o agencia — no solo en el club de tareas, sino también en la escuela y en su casa, que son los otros dos principales escenarios en donde son agentes - se encuentra delimitada por el modelo, suposiciones y significados que socialmente se asignan al ser niño-estudiante. Sus comportamientos y verbalizaciones recogidos durante la investigación así lo confirman.

Producto del trabajo de campo en este club de tareas, se obtuvieron verbalizaciones de los niños a través de las cuales se buscó identificar las características de los contextos concretos en los que se desenvuelven y que no solo están estructurados de una manera particular, sino que estructuran a los menores constriñendo su agencia. Algunas de estas verbalizaciones, elegidas 
por lo significativas que resultan en la noción de agencia, se incorporan de manera paralela a la descripción del lugar y dinámicas en su interior, con la intención de exponer los resultados del trabajo de campo en dos planos: el que resultó de la observación y el que derivó de los diálogos con los niños.

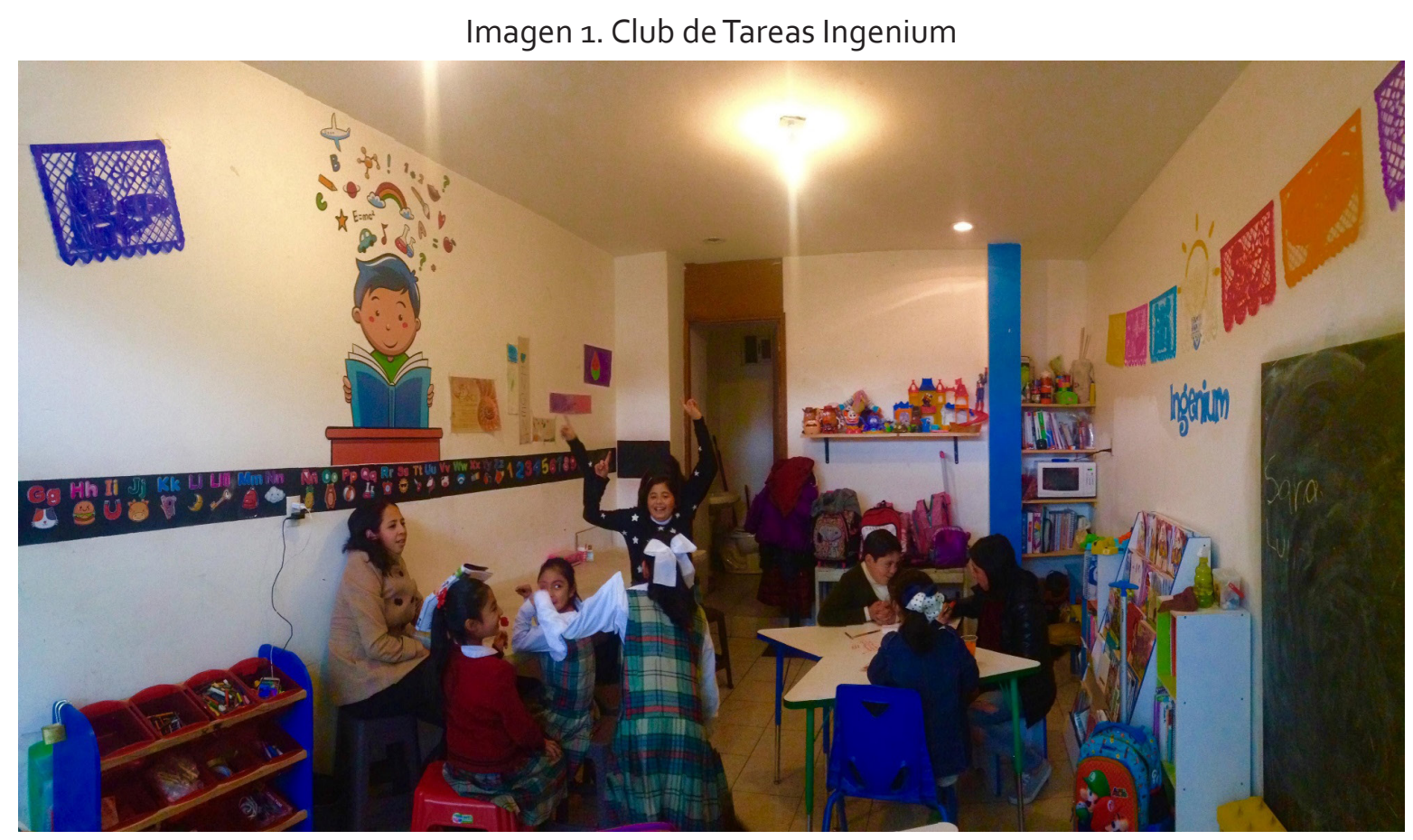

(Trabajo de campo, junio de 2018).

\section{Resultados}

"A mí me inscribieron porque peleaba mucho con mi mamá al hacer la tarea", dice Raúl, conocido por sus compañeros del club como "Chupete". Él es de los chicos que acuden al Club desde que éste abrió sus puertas. Para aquel momento contaba sólo con escasos cuatro años de edad, hoy ya está en cuarto año de primaria y sigue acudiendo todas las tardes al club.

El Club de Tareas Ingenium no está respaldado por ninguna institución, dependencia o autoridad en materia educativa. Es básicamente un negocio que presta servicios a través de dos personas que forman parte de una familia (Jimena Hernández y Daniela Hernández), la primera de ellas es la fundadora y quien más tiempo ha estado en el club; la segunda se incorporó posteriormente. Durante el tiempo que duró el trabajo de campo en dicho lugar, el número de niños que atendían osciló entre 15 y 18, de ambos sexos, con edades que van de 3 a 12 años. Los 
infantes que asisten al club lo hacen en diferentes horarios (distribuidos en intervalos de 120 minutos) de lunes a viernes de: 9:00 a 11:00, 13:00 a 15:00, 15:00 a 17:00 y 17:00 a 19:00. El costo aproximado es de 600 pesos al mes, lo cual puede variar en función de los servicios que se le presten al menor, que pueden incluir alimentos, los cuales por día tiene un costo de 25 pesos.

La docente A (Jimena Hernández) se encarga de regularización, lecto-escritura y matemáticas, mientras que la docente $B$ (Daniela Hernández) se encarga de actividades de lecto-escritura, matemáticas e inglés. La sede del club es una casa-habitación, propiedad de la familia a la que pertenecen las dos personas que atienden a los niños. Este inmueble fue adecuado para simular un aula, en un espacio de cinco metros de largo por cuatro metros de ancho, con un baño que tiene lavamanos y un retrete. También cuentan con un horno de microondas para los infantes que comen en el establecimiento, tal como se representa a continuación:

Imagen 2. Croquis de distribución del espacio

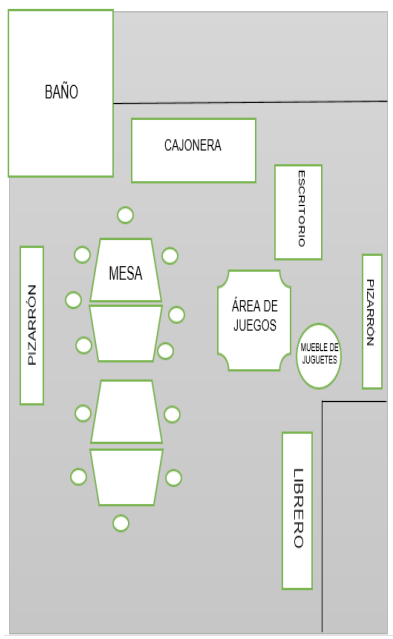

Fuente: Elaboración propia con base en trabajo de campo, junio de 2018.

Dicho espacio se encuentra equipado con una serie de materiales característicos de un espacio educativo, tal como se detalla enseguida: 
Tabla 1. Relación de mobiliario y materiales educativos

\begin{tabular}{|l|l|}
\hline \multirow{4}{*}{ Mobiliario escolar } & 1 escritorio \\
& 2 mesas (se dividen y forman cuatro) \\
2 pizarrones & Aproximadamente 1o sillas para infante \\
& Mueble para guardar juguetes y material didáctico \\
& Cajonera para guardar útiles escolares \\
& Mueble bibliotecario. \\
\hline \multirow{4}{*}{ Materiales didácticos } & Libros de: matemáticas, biología, literatura, lecto-escritura y cuentos \\
& Rompecabezas \\
& Abecedario de cartón \\
& Yenga \\
& Números \\
& Dados. \\
\hline \multirow{3}{*}{ Útiles escolares } & Lápices \\
& Colores \\
& Crayones \\
& Pegamento y Tijeras \\
& Regla. \\
\hline
\end{tabular}

"A mí me gusta venir porque no trabajamos", dice irónicamente y entre risas Alma, cuando trata de explicar cómo es que le ha venido encontrando el gusto a asistir al club de lunes a viernes al salir de la escuela. En el club come, porque al salir del colegio no va a su casa sino directo la lleva su papá a Ingenium para luego recogerla por la tarde-noche.

A los padres de familia se les ofrecen servicios para la satisfacción de ciertas necesidades de los niños en áreas como matemáticas, habilidades de lecto-escritura, inglés y regularización. Los materiales publicitarios, a través de los cuales se ofrecen los servicios del club, establecen que tiene como misión "brindar un servicio profesional en donde los niños tengan el acompañamiento necesario de docentes, para poder realizar actividades académicas, así como también reforzar valores, aprender el cuidado de la naturaleza y la buena interacción social" (Trabajo de campo, julio 2018). Lo anterior fue contrastado con el testimonio de las dos personas que atienden el club, quienes aseguraron que la Visión de su empresa consiste en "ser una institución especializada y reconocida por su buen desempeño en la realización de tareas escolares, el reforzamiento de valores, sensibilización ante la naturaleza y la buena interacción social con las demás personas" (Trabajo de campo, julio 2018).

"Esta es la última vez que te hablo, a la segunda te pondré recado..." dice con tono sarcástico Azul, imitando a la docente A (Jimena) cuando trata de poner orden en el Club, pero — dice - "ni nos hace nada, ni pone recado ni nada".

\section{Diólo oos}


Cada día las actividades en el club de tareas inician alrededor de las 8:45 am, unos minutos antes de que arriben los infantes que estudian en el turno vespertino y acuden a hacer su tarea a partir de las 9 de la mañana. Los minutos que trascurren entre la apertura del lugar y el arribo de los niños es empleado para realizar aseo y acomodo del mobiliario. Al llegar los primeros niños, les permiten jugar durante unos 15 minutos y luego se "ponen a trabajar". Las actividades que realizan —dicen las docentes del lugar — están en función de las necesidades del infante: regularización, apoyo en la realización de tarea, clase de lecto-escritura, matemáticas o inglés. Cada que terminan una actividad se les otorga un tiempo de 10 minutos para jugar.

Los niños que llegaron a las 9:00 terminan alrededor de las 11:00. Después, las encargadas del club tienen un tiempo "libre", para reanudar las actividades a las 13:00, pero parte de él lo emplean para preparar los alimentos que ofrecerán a los niños que nuevamente comenzarán a llegar a partir de las 13:00. En este nuevo turno, conforme van arribando al lugar, los infantes inician las actividades (posterior a los 15 minutos otorgados para jugar). A las 3 de la tarde se detienen las actividades a fin de que los niños y docentes que se encuentran presentes puedan comer. Para ello, los propios chicos primero recogen los materiales utilizados que se encuentren en las mesas para tener espacio libre y ahí colocan ellos mismos los platos y vasos. Del mismo modo, al término de la comida, los infantes se turnan para limpiar el lugar donde comieron, para después continuar con las actividades.

- ¿Y en tu casa no te regañan por esos "tachecitos"? (es como se refieren las niñas a las marcas en el cuaderno que les colocan las maestras de su escuela).

—A mí sí me regañan y me pegan —dice Azul.

Conforme transcurre la tarde, llegan otros niños que tienen un horario de 16:00 a 18:00, o de 17:00 a 19:00. A todos los miembros del club se les otorgan de 10 a 15 minutos para jugar, al término de cada actividad que hayan desarrollado. Pero ese tiempo puede disminuir o eliminarse en función del interés y empeño que hayan puesto en la actividad. Aproximadamente, a las 19:00 horas terminan las labores en el club. Cada niño debe colocar en orden todo lo que se encuentre fuera de su lugar y que haya ocupado para que de este modo puedan reanudarse las labores al día siguiente. Pero no son pocos los casos en que algún niño o niña del club debe esperarse más tiempo hasta que pasen a recogerlo. Si es así, puede que lo ingresen a la casa de la que forma parte la pequeña aula habilitada para el club de tareas.

"La maestra siempre dice: te voy a poner recado si sigues actuando así,, recuerda Alma cuando platicamos sobre su maestra en la escuela en donde está en cuarto año de primaria. Para ella y otros de sus compañeros, los maestros siempre les amenazan con darle la queja a sus papás que son quienes finalmente pueden regañarlos o castigarlos de alguna manera. 
El club de tareas tiene tanto un reglamento para los padres de familia como otro para los niños y niñas que acuden cotidianamente. Para los primeros, el reglamento dispone "puntualidad en los pagos", "respetar el horario contratado" tanto de entrada como de salida y asegurarse de que "si su hijo(a) necesita realizar algún trabajo en particular y necesita material específico (cartulinas, hojas blancas, papel cascarón, etc.), deberá comprarlo antes de asistir al club". Especialmente, se recomienda que "deberá avisar con dos semanas de anticipación el periodo de exámenes, para que su hijo(a) tenga buen margen de tiempo y pueda prepararse para los mismos durante su estadía en el club".

Por lo que hace al reglamento que deben observar los asistentes al club, este dispone, entre otras cosas, respetar a los otros, hablar en voz baja y siempre ser amables, terminar la tarea primero, ser responsable, cuidar los libros y regresarlos a su lugar, limpiar el área donde haya trabajado, tomar todas sus pertenencias al salir, ordenar los juguetes (en caso de haber jugado), lavarse las manos antes de comer y después del ir al baño, no correr, no gritar, no decir groserías y respetar al profesor.

Este último reglamento resulta un indicio de que el club de tareas está fungiendo como extensión de la escuela y del hogar, pues se disponen las actividades, deberes y responsabilidades del infante de tal modo que se correspondan con el comportamiento esperado tanto en su hogar como en la escuela a la que acuden oficialmente. El trabajo de campo realizado confirma que en el club de tareas se brindan servicios correspondientes con la educación no formal, pero de manera implícita y no siempre externalizada, hay una educación informal pues las encargadas del lugar con frecuencia buscan aconsejar, escuchar, recomendar o hasta brindar abrazos y caricias a los niños, con lo cual parecieran fungir en ocasiones como padres y/o hermanos.

- ¿Qué te dijo la miss?

-O te pones a trabajar o ahorita que venga tu mamá le voy a decir...

- ¿Y crees que sí le diga?

-Naaaa.

En las varias semanas que se estuvo colaborando en el club de tareas fue notorio que el tipo de comportamiento que se presentó de manera repetitiva entre los niños fue el que para espacios escolares ha sido calificado como disruptivo: "que puede considerarse parte de la indisciplina, nos referimos a los comportamientos que impiden llevar el ritmo de la clase, que obstaculizan la labor docente del profesorado y pueden llegar a interferir en el proceso de aprendizaje del alumnado" (De la Peña, 2003: 16). Lo que casi todo el tiempo hacen los menores en el club son: ruidos corporales, ruidos con objetos, levantarse constantemente de su sitio y deambular por el lugar, burlarse de los compañeros, decir groserías, arrebatar el material a otros, no acatar indicaciones y/o responder a la profesora e interrumpir a los compañeros.

Diálo@os 
Como en casi todo lugar donde concurren varios agentes, hay una especie de organización espontánea que coloca a cada uno en un sitio. Por ejemplo, en el club de tareas se identificaron grupos cerrados (infantes que "se juntan" porque comparten ciertas características). Respecto a la consecuencia que hay sobre las acciones "disruptivas" de los infantes, el registro fue invariable: la docente A solo advierte que de seguir así habrá doble trabajo o disminución del tiempo que disponen para jugar. La docente $B$, de inmediato ordena más trabajo o les deja sin tiempo para jugar. Lo anterior debe ponerse en perspectiva, recordando que este no es un espacio regulado por alguna institución o normatividad, lo que permite que sea absolutamente arbitraria la decisión de cómo actuar frente a las conductas de los niños.

— ¿Por qué andas recogiendo todo, Cloe? -le preguntamos porque es algo que siempre hace en el club, sobre todo lo que deja tirado su hermana Maya.

- Mi hermana es bien desordenada y yo tengo que hacer todo el quehacer... En la casa se la pasa de floja — dice Cloe respecto de su hermana.

Maya y Cloe son gemelas, tienen 7 años y pasan alrededor de seis a siete horas en el club y hacen de todo durante este tiempo: su tarea escolar, actividades para reforzar sus conocimientos en lecto-escritura y matemáticas, ahí comen, siempre ayudan a ordenar y apoyan a las profesoras en lo que les pidan. El resto de los niños acude de dos a tres horas regularmente. Cabe resaltar que, de acuerdo a los datos recabados durante la investigación, los niños que han permanecido más tiempo en el club (que son nueve en total) viven bajo el cuidado de sus mamás. Solo dos de esas nueve madres están casadas, el resto se dijeron solteras. Por otra parte, siete de ellas tienen un grado de escolaridad en licenciatura, las dos restantes solo la preparatoria. El rango de edad de estas madres es de 30 a 37 años. Y en cuanto a su ocupación profesional, solo dos se dedican a ser amas de casa, mientras que el resto tiene una ocupación profesional, desde abogadas y administradoras hasta docentes o empleadas. Lo anterior permite correlacionar la asistencia de los menores al club de tareas con las nuevas dinámicas familiares y laborales de la sociedad mexicana que ya ha sido documentado por algunos estudios (Samaniego, 2009).

Como parte de las actividades de investigación encaminadas a identificar las maneras en que los niños justifican su actuar, se empleó el sociodrama como recurso de investigación (Cunha, 2015), buscando recrear los contextos concretos estructurados y estructurantes donde los menores desarrollan su agencia: familia, escuela y club de tareas. Se sugirió a los niños participar de una forma lúdica imitando a sus mamás y papás, a sus maestras de la escuela y a las docentes del club de tareas. Algunos de los chicos se ofrecieron a actuar como alumnos o como hijos y otros a representar a los agentes adultos con quienes más interactúan. Aquí se trascriben los fragmentos más significativos. 


\section{Recreación de su escuela:}

Shavy: ¡Miss Aurora! (refiriéndose a su compañera Alma).

Miss Aurora (Alma): Ponte a trabajar bien.

Shavy: Ya terminé. Póngame otras diez multiplicaciones (en tono burlón).

Shavy: Maestra Aurora, dice la miss Pao que a él le ponga sumas (refiriéndose a su hermano Cristian).

Miss Aurora (Alma): ¿Cuántas hiciste? No que... solo era una, borra la que quieras. (risas...).

Cristian: Pues mira aquí están (dirigiéndose a la miss Aurora).

Miss Aurora (Alma): ¿De cuántas cifras sabes?

Cristian: De una...

Interviene la maestra Jimena: ¡Sí sabes hacer de esas! (dirigiéndose a Cristian).

Raúl: Miss, ya vamos a jugar. (dirigiéndose a la maestra Jimena).

Maestra Jimena: ¡Por eso, ya apúrate Raúl, apúrate!

(Raúl ya tenía que comer para poder irse a la hora de salida y poder hacer la actividad.

Siguen actuando...).

Miss Aurora (Alma): ¡Pásame tu libreta! (gritándole a Shavy).

Shavy: ¡No quiero! (riéndose).

Interviene la compañera Maya: ¡Miss, Raúl está tirando la sopa! (dirigiéndose a la maestra Jimena).

Miss Aurora (Alma): ¿Por qué? Te voy a poner recado, si sigues actuando así. Te dije que solo era una...

Miss Aurora (Alma): A los demás compañeros, a ver enséñenme.

Miss Aurora (Alma): Felicidades tienes 10 (le califica a su alumna Yare).

Shavy y Cristian: ¿Y por qué ella tiene 10?

Miss Aurora (Alma): ¿Y tú qué, ya las hiciste? ¿Ya las hiciste? ¡Apúrate!

\section{2da Representación del hogar}

Actores: Mamá, Andy; Papá, Ángel; Hijas, Sandy y Yuri.

Andy (Mamá): Hija, vete al parque; y tú acompáñala (refiriéndose a su hermana Yuri).

Andy (Mamá): Y tú también Ángel acompáñalas.

Ángel: Vámonos al parque...

Ya regresaron del parque, 5 minutos después...

Andy (Mamá): Ya váyanse, a dormir. Ya, Sandy, vete a dormir.

Alma (Papá): ¿A ver niña, que hiciste?

Sandy (Hija): Yo no hice nada... (gritando).

Alma (Papá): ¿Cómo que no hiciste nada? ¡Y no me hables con esa voz!

Sandy (Hija): ¿Y si no quiero?

Alma (Papá): No me faltes al respeto, niña. A tu cuarto, dije que, a tu cuarto, sin pretextos. O te quedas sin televisión y sin Tablet. Te la voy a quitar para que no puedas usarla.

\section{Diólo os}


Alma (Papá): ¡Y a tu cuarto, dije!... (gritando).

Andy (Mamá): Y ya vete a dormir (refiriéndose a Sandy), que mañana tienes que ir a tu escuela.

Alma (Papá): Ya levántense... ¿Ya llevan su agua? ¿Ya llevan su lunch? Apúrense...

Andy (Mamá): Ten tu agua y tu lunch. Ya apúrense...

Alma (Papá): Órale, a su escuela... (con tono apresurado).

\section{Representación del club de tareas}

Actores: Profesora Jimena, Azul; Profesora Daniela, Maya; Alumnas, Alma y Cloe.

Azul (Profesora Jimena): A ver niña, sácame tu libro de ciencias por favor. Sácame el libro, por favor. No te voy a estar repitiendo dos veces.

Azul (Profesora Jimena): Rápido, o ya guarda tus cosas. Ahorita que venga tu mamá le voy a decir.

Azul (Profesora Jimena): Apúrale, apúrale a hacer tu tarea. Escucha ya y pon atención.

Azul (Profesora Jimena): Ahorita que vengan por ti, voy a dar la queja. Porque no haces la tarea. Ya guarda tus libros.

Alma (Alumna): Yo no voy a estar sacando, ni guardando los libros.

Azul (Profesora Jimena): Voy por una hoja, ya apúrate... Y vas a escribir lo más importante. Y lo dibujas, por favor.

Azul (Profesora Jimena): Ya dame lo que estás haciendo, o ahorita que venga tu papá le daré la queja.

Azul (Profesora Jimena): Esta es la última vez que te hablo, a la segunda ya te pondré recado.

\section{Discusión}

El Club de Tareas Ingenium es una empresa familiar. Surgió como una alternativa de autoempleo para dos hermanas que tras concluir sus estudios de licenciatura en Trabajo Social (docente A) y Turismo (docente B), vieron la posibilidad de emprender, desde casa, un negocio que les permitiera obtener recursos. Ha tenido varias etapas, incluso se ha mudado de instalaciones y ha crecido en cuanto a asistentes. Esta actividad no solo es - como ya se mencionó- un modelo de negocios con cierto auge, también es una actividad que está produciendo un contexto concreto donde la agencia de los niños es estructurada de modos distintos que en espacios como el hogar o la escuela regular. Esto fue identificado mediante los encuentros etnográficos que se emprendieron. Las voces de estos niños dan cuenta de que el club de tareas es un lugar donde tienen una capacidad de actuar distinta a los papeles clásicos de hijo y alumno. El club de tareas no implica calificaciones (como en la escuela) ni tampoco castigos (como en la casa); ahí pueden aprender cosas, pero también jugar, hacer amistad, encontrar alguien que — sin ser de su familia o su profesor en la escuela oficial- se preocupe por sus cosas, sus tareas, sus calificaciones y hasta comer o pasar el tiempo en compañía. En otras palabras, cuando se sitúan como actores en este espacio, su capacidad de actuar quizá no escapa a las relaciones de subordinación, 
adultocéntricas, dentro de un proceso más amplio de jerarquización social en el que se desenvuelven los niños en nuestra sociedad, pero sí encuentran condiciones diferenciadas al no estar presentes los mecanismos censores que son las calificaciones y los castigos.

Hacer la tarea en casa requeriría que en ella estén presentes los padres, porque la esencia de ese ejercicio - según Cooper (1994) - es vincular a estos últimos con la actividad escolar, pero en el caso de los chicos del club de tareas, o bien sus papás no están o no ha sido posible que con ellos puedan realizarla. Y esto tiene que ver con las características de las familias a las que pertenecen y las ocupaciones de sus padres, como se documentó páginas atrás.

Dado que los menores que fueron considerados para este trabajo desarrollan su agencia básicamente en tres contextos concretos (escuela, familia y club de tareas), el ejercicio del sociodrama nos revela lo que pueden hacer ellos, pero también la agencia de los adultos con los que interactúan y negocian permanentemente. Por esta razón, al identificar dentro de sus verbalizaciones aquellas acciones que involucran directamente la capacidad de actuar que tienen ellos, sus padres y sus maestros, en la siguiente tabla se concentran aquellas expresiones que permiten detectar hasta dónde poseen la capacidad de acción estos niños y los referentes que establecen los márgenes o límites. Mediante dicha tabla se busca explicitar las innegables relaciones asimétricas, basadas en el adultocentrismo que -como afirma Magistris (2018) - incorporan cadenas de jerarquías que involucran adultos con diferentes fuentes de legitimidad y que limitan la agencia de estos niños. 
Tabla 2. Relaciones asimétricas

\begin{tabular}{|c|c|c|c|}
\hline Referente & Fragmentos & Agentes Involucrados & Implicaciones en la agencia \\
\hline $\begin{array}{l}\text { Alusión a los pa- } \\
\text { dres de familia } \\
\text { (autoridad) }\end{array}$ & $\begin{array}{l}\text { "Te voy a poner recado, si } \\
\text { sigues actuando así..." } \\
\text { "Ahorita que venga tu } \\
\text { mamá le voy a decir..." } \\
\text { "Ahorita que vengan por } \\
\text { ti, daré la queja..." } \\
\text { "Esta es la última vez que } \\
\text { te hablo, a la segunda te } \\
\text { pondré recado..." } \\
\text { "O te pones a trabajar } \\
\text { o ahorita que venga tu } \\
\text { mamá le voy a decir..." }\end{array}$ & $\begin{array}{l}\text { Mamá (de manera in- } \\
\text { directa) } \\
\text { Papá (de manera indi- } \\
\text { recta) } \\
\text { Abuela/o (de manera } \\
\text { indirecta) }\end{array}$ & $\begin{array}{l}\text { Límites } \\
\text { Responsabilidad } \\
\text { Eludir responsabilidades } \\
\text { Autoridad }\end{array}$ \\
\hline $\begin{array}{l}\text { Alusión a una } \\
\text { cuestión acadé- } \\
\text { mica y actividad } \\
\text { extra escolar }\end{array}$ & $\begin{array}{l}\text { "Póngame otras diez mul- } \\
\text { tiplicaciones..." } \\
\text { "Nos va a aplicar tacheci- } \\
\text { tos, y nos van a bajar cali- } \\
\text { ficación..." } \\
\text { "Ponte a trabajar..." } \\
\text { "Ponte a hacer la tarea..." } \\
\text { "A ver niña, sácame tu } \\
\text { libro de ciencias por favor. } \\
\text { No te voy a estar repitien- } \\
\text { do dos veces. Saca el libro } \\
\text { por favor..." } \\
\text { "Ya dame lo que estás ha- } \\
\text { ciendo (tarea o trabajo) o } \\
\text { ahorita que venga tu papá } \\
\text { le daré queja..." } \\
\text { "Y porque no trabaja- } \\
\text { mos..." } \\
\text { "Porque no haces tú tarea, } \\
\text { ya guarda tus libros..." }\end{array}$ & $\begin{array}{l}\text { Maestra Jimena (direc- } \\
\text { tamente) } \\
\text { Maestra Daniela (direc- } \\
\text { tamente) } \\
\text { Maestra de escuela bá- } \\
\text { sica (indirectamente). }\end{array}$ & $\begin{array}{l}\text { Enseñanza } \\
\text { Aprendizaje } \\
\text { Autoridad } \\
\text { Respeto } \\
\text { Obligación/Des obligación }\end{array}$ \\
\hline
\end{tabular}




\begin{tabular}{|c|c|c|c|}
\hline $\begin{array}{l}\text { Alusión a una } \\
\text { cuestión en el } \\
\text { hogar }\end{array}$ & $\begin{array}{l}\text { "¿A ver niña, que hiciste?" } \\
\text { "No me faltes al respeto } \\
\text { niña..." } \\
\text { "A tu cuarto, dije que, a tu } \\
\text { cuarto, sin pretextos..." } \\
\text { "Te quedas sin televisión y } \\
\text { sin Tablet. Te la voy a qui- } \\
\text { tar para que no la uses..." } \\
\text { "Órale, a su escuela..." } \\
\text { "Me inscribieron, porque } \\
\text { peleaba mucho con mi } \\
\text { mama al hacer la tarea..." } \\
\text { "A mí sí me regañan y pe- } \\
\text { qan..." }\end{array}$ & $\begin{array}{l}\text { Mamá (de manera di- } \\
\text { recta) } \\
\text { Papá (de manera di- } \\
\text { recta) }\end{array}$ & $\begin{array}{l}\text { Autoridad } \\
\text { Responsabilidad } \\
\text { Respeto } \\
\text { Valores }\end{array}$ \\
\hline
\end{tabular}

Fuente: Elaboración propia a partir de trabajo de campo 2019.

Los adultos establecen límites para la agencia de los niños, pero esta es ejecutada por ellos moviéndose dentro de los márgenes que les han establecido. En el club de tareas, como contexto concreto donde se sitúan como actores, ellos ejecutan la agencia que les estructura tanto en la escuela como en la casa, pero lo llevan a cabo en un espacio donde hay que hacer"cosas de la escuela", pero también "cosas de la casa" sin la presencia de mecanismos que en los otros espacios directamente controlan su capacidad de actuar, como son las calificaciones y los castigos. De acuerdo con las expresiones mostradas en la tabla anterior, queda claro que los niños reconocen los límites particulares para su accionar en cada espacio y proceden en consecuencia. La educación no formal que en el club podría estarse identificando, se articula con la informal: las encargadas del club de tareas asumen esa necesidad de mantener los márgenes para la agencia de los niños y ellos responden como si estuvieran interactuando con los papás o con los maestros del sistema escolar, aunque se muestran sabedores de que hay un poco más de "flexibilidad" porque propiamente no hay calificaciones ni castigos, solo la amenaza permanente de "mandar recado" o "decirle" a sus padres sobre algo que hayan realizado y que se escapa de esos límites para su capacidad de actuar.

\section{Conclusiones}

En el caso de los niños que acuden al club de tareas, su agencia está encontrando un contexto concreto muy particular: es un espacio educativo emergente, propio de condiciones socioeco- 
nómicas presentes en ciertos sectores de la sociedad mexicana contemporánea (familias monoparentales, la mujer integrada al ámbito laboral, exigencias educativas que motivan a pensar en un aprendizaje constante y un mercado de profesionales que ofrecen servicios educativos) en donde su capacidad de actuar tiene particularidades distintas a las que encuentran en la familia y en la escuela; los niños se dan cuenta de ello y el resultado es un tipo de agencia infantil que no es ajena a las relaciones de poder de una sociedad adultocéntrica, pero que negocia de modos muy particulares lo que puede hacer en dicho espacio, específicamente, al no estar presentes dos mecanismos censores básicos: las calificaciones y los castigos.

Los datos permiten afirmar que los clubes de tareas están identificando un tipo de "necesidad" para ciertos padres de familia (aquellos que por cuestiones laborales, de estructura de su grupo familiar, de movilidad y distancia en las grandes ciudades o el tipo de residencia en la que viven, no pueden estar presentes durante las horas en las que se hacen las tareas escolares) y la están convirtiendo en una oportunidad laboral para profesionales que pueden emprender desde su casa un negocio que brinde un servicio educativo. En tanto, para los niños se ha venido constituyendo un espacio donde ellos pueden desarrollar su agencia y expandirla, siempre dentro de los márgenes que el mundo adulto les pone. Pero al entrar en contacto con adultos que no son ni sus padres ni sus maestros, desarrollan un tipo de agencia en la que pueden ser un poco hijos, un poco alumnos, un poco amigos, un poco compañeros.

\section{Referencias}

Alto Nivel (2010). 10 tips para abrir tu negocio. https://www.altonivel.com.mx/empresas/ emprendedor/10-tips-para-abrir-tu-negocio/

Arellano, D. (2012). El juego como estrategia didáctica para la enseñanza-aprendizaje del idioma inglés en alumnos de nivel primaria que acuden al club de tareas "Alegría". (Tesis de licenciatura). Universidad Pedagógica Nacional, México. http://200.23.113.51/pdf/28423.pdf

Bloor, D. (2014). Conocimiento e imaginario social. Barcelona: Gedisa.

Bourdieu, P. (1991). El sentido práctico. Madrid: Taurus.

Canfux, V. (2000). La pedagogía tradicional. En Tendencias pedagógicas en la realidad educativa actual (pp. 5-10). La Habana: Editorial Universitaria/Universidad Juan Misael Saracho

Cooper, H. (1994). The battle over homework: an administrator's guide to setting sound and effective policies. California: Corwinpress, Inc.

Cunha, M. (2015). Sociodrama temático: un procedimiento de investigación. Revista Brasileira de Psicodrama, 23(1), 14-22.

De la Peña, V., E., Hernández y F. Rodríguez (2003). “Comportamiento asertivo y adaptación social: Adaptación de una escala de comportamiento asertivo (CABS) para escolares de enseñanza primaria (6-12 años)". Rema, 8(2), 11-25. 
Elías, M. (2015). La cultura escolar: aproximación a un concepto complejo. Revista Electrónica Educare, 19(2), 285-301. https://www.revistas.una.ac.cr/index.php/EDUCARE/article/ view/6591/6693

Ema, L. (2004). Del sujeto a la agencia (a través de lo político). Atenea Digital, (6), 1-24. file:///C:/ Users/josé/Downloads/Dialnet-DelSujetoALaAgenciaATravesDeLoPolitico-858650.pdf

Entrepreneur (2008). Club de tareas. https://www.entrepreneur.com/article/260836

Fabian, J. (2007). Memory against culture. Argu-ments and reminders. Durham: Duke University Press.

Guber, R. (2011). La etnografía. Método, campo y reflexividad. Buenos Aires: Siglo XXI.

Giddens, A. (1986). The constitution of society. Cambridge: Polity Press.

Hernández, M. (2003) Propuesta de intervención para problemas de adicción en un taller de tareas (tesina para obtener el título en Psicología educativa). Universidad Pedagógica Nacional. http://200.23.113.51/pdf/19883.pdf

Ideas de Negocios (2019). Club de tareas para niños en edad escolar. Negocios novedosos desde casa. https://ideasdenegocios.com.ar/negocio-club-tareas-ninos-edad-escolar.htm

Ingold, T. (2017). Suficiente con la etnografía. Revista Colombiana de Antropología, 53(2), 143-159. (2013). Making: Anthropology, Archaeology, Art, and Architecture. Abingdon: Routledge.

INEE (2009), Panorama Educativo de México: Indicadores del Sistema Educativo Nacional 2009, Educación Básica. México: INEE.

(2014). Panorama Educativo de México: Indicadores del Sistema Educativo Nacional 2014, Educación básica y media superior. México: INEE.

(2015). Panorama Educativo de México: Indicadores del Sistema Educativo Nacional 2015, Educación básica y media superior. México: INEE.

Magistris, G. (2018). La construcción del niño como sujeto de derechos y la agencia infantil en cuestión. Journal de Ciencias Sociales, Revista Académica de la Facultad de Ciencias Sociales de la Universidad de Palermo, 6(11), 6-28. https://dspace.palermo.edu/ojs/index.php/jcs/article/ view/819/736

Martínez, F. (1996). La Investigación Educativa en México en el contexto latinoamericano. http:// www.fmrizo.net/fmrizo pdfs/capitulos/C 0131996 La IE en Mexico y AL-De Landsheere.pdf

Milstein, D., et al. (2011). Encuentros etnográficos con niñ@s y adolescentes. Buenos Aires: Ides/ Miño y Dávila.

Nussbaum, M. (2012). Crear capacidades. Propuesta para el desarrollo humano. Barcelona: Paidós.

Pontón, C. (2002). Constitución conceptual de la educación como objeto de estudio y su impacto en la formación de profesionales de la educación. Perfiles Educativos, 24(98), 117-126.

Rosas, P. (2018). La investigación educativa: concepto y antecedentes. Eutopía, 11(28), 57-61.

Salinas, M., y F. Molina (2009). Dspace. http://dspace.ups.edu.ec/bitstream/123456789/132/3/Capitulo2.pdf 
Sánchez-Parga, J. (2010). El oficio de antropólogo. Quito: Abya Yala/Universidad Politécnica Salesiana.

Solano, A. (2001). Propuesta del programa de "Club de Tareas" como desarrollo del trabajo profesional del pedagogo. Informe académico para la obtención del título de licenciado en pedagogía. México: UNAM. http://132.248.9.195/pd2001/297768/Index.html

Samaniego, S. (2009). Armonización entre los ámbitos laboral y familiar en México. México: Centro de Estudios para el Adelanto de las Mujeres y la Equidad de Género. http://cedoc.inmujeres.gob.mx/lgamvlv/ceameg/armonizacion laboral familiar.pdf

Trilla J. (2009). La Educación no Formal. Aportes a las prácticas de Educación No Formal desde la Investigación educativa. Montevideo: Dirección Educativa del Ministerio de Educación y Cultura, 99. 